\title{
Guideline update for the performance of fusion procedures for degenerative disease of the lumbar spine. Part 14: Brace therapy as an adjunct to or substitute for lumbar fusion
}

\author{
Andrew T. Dailey, M.D., ${ }^{1}$ Zoher Ghogawala, M.D., ${ }^{2}$ Tanvir F. Choudhri, M.D., ${ }^{3}$ \\ William C. Watters III, M.D., ${ }^{4}$ Daniel K. Resnick, M.D., ${ }^{5}$ Alok Sharan, M.D. ${ }^{6}$ \\ Jason C. Eck, D.O., M.S., ${ }^{7}$ Praveen V. Mummaneni, M.D., ${ }^{8}$ Jeffrey C. Wang, M.D., 9 \\ Michael W. Groff, M.D., ${ }^{10}$ Sanjay S. Dhall, M.D., ${ }^{8}$ and Michael G. Kaiser, M.D. ${ }^{11}$ \\ ${ }^{1}$ Department of Neurosurgery, University of Utah, Salt Lake City, Utah; ${ }^{2}$ Alan and Jacqueline Stuart Spine \\ Research Center, Department of Neurosurgery, Lahey Clinic, Burlington, and Tufts University School of \\ Medicine, Boston, Massachusetts; ${ }^{3}$ Department of Neurosurgery, Icahn School of Medicine at Mount Sinai, \\ New York, New York; ${ }^{4}$ Bone and Joint Clinic of Houston, Houston, Texas; ${ }^{5}$ Department of Neurosurgery, \\ University of Wisconsin, Madison, Wisconsin; ${ }^{6}$ Department of Orthopaedic Surgery, Montefiore Medical \\ Center, Albert Einstein College of Medicine, Bronx, New York; ${ }^{7}$ Center for Sports Medicine and \\ Orthopaedics, Chattanooga, Tennessee; ${ }^{8}$ Department of Neurological Surgery, University of California, San \\ Francisco, California; ${ }^{9}$ Department of Orthopaedic Surgery, Keck School of Medicine, University of \\ Southern California, Los Angeles, California; ${ }^{10}$ Department of Neurosurgery, Brigham and Women's \\ Hospital, Boston, Massachusetts; and ${ }^{11}$ Department of Neurosurgery, Columbia University, New York, \\ New York
}

The utilization of orthotic devices for lumbar degenerative disease has been justified from both a prognostic and therapeutic perspective. As a prognostic tool, bracing is applied prior to surgery to determine if immobilization of the spine leads to symptomatic relief and thus justify the performance of a fusion. Since bracing does not eliminate motion, the validity of this assumption is questionable. Only one low-level study has investigated the predictive value of bracing prior to surgery. No correlation between response to bracing and fusion outcome was observed; therefore a trial of preoperative bracing is not recommended. Based on low-level evidence, the use of bracing is not recommended for the prevention of low-back pain in a general working population, since the incidence of low-back pain and impact on productivity were not reduced. However, in laborers with a history of back pain, a positive impact on lost workdays was observed when bracing was applied. Bracing is recommended as an option for treatment of subacute low-back pain, as several higher-level studies have demonstrated an improvement in pain scores and function. The use of bracing following instrumented posterolateral fusion, however, is not recommended, since equivalent outcomes have been demonstrated with or without the application of a brace.

(http://thejns.org/doi/abs/10.3171/2014.4.SPINE14282)

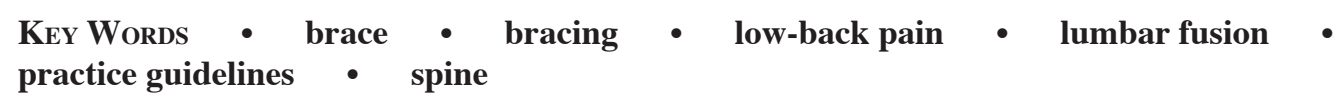

\section{Recommendations}

There is no evidence that conflicts with the previous recommendations published in the original version of the guidelines for the use of lumbar bracing in the treatment of low-back pain.

\footnotetext{
Abbreviations used in this paper: DPQ = Dallas Pain Questionnaire; ODI = Oswestry Disability Index; PLF = posterolateral lumbar fusion; RMDQ = Roland-Morris Disability Questionnaire; RSA $=$ roentgen stereophotogrammetric analysis; SF-12 $=12$-Item Short Form Health Survey; SF-36 = 36-Item Short Form Health Survey; $\mathrm{TEPF}=$ temporary external pedicle fixation; VAS = visual analog scale.
}

\section{Grade B}

The prescription of a lumbar brace is useful for the secondary prevention of low-back pain by reducing the number of days of self-reported low-back pain and days lost to work in laborers with a history of low-back pain (single Level I study and multiple Level II studies).

For primary prevention, the use of a lumbar corset does not prevent the development of low-back pain in the general working population (multiple Level II studies).

For patients presenting with low-back pain, the prescription of a lumbar support in the setting of subacute pain $(<6$ months' duration) reduced the visual analog scale (VAS) pain score and medication usage and im- 


\section{A. T. Dailey et al.}

proved functional disability at 30-90 days (single Level I study and multiple Level II studies).

\section{Grade C}

The use of a brace following instrumented posterolateral lumbar fusion (PLF) for lumbar spondylosis is not supported due to equivalent outcomes with and without bracing (single Level II study).

Finally, a trial of preoperative bracing is not predictive of outcome for lumbar fusion in the setting of lowback pain (Level III evidence).

\section{Rationale}

Lumbosacral orthotics have been used for the prevention and treatment of a wide variety of degenerative disorders of the lumbar spine. ${ }^{10,24,33}$ In addition, they have been used to improve outcome following lumbar fusion surgery and to aid in the selection of appropriate surgical candidates. ${ }^{8}$ The potential mechanisms of action remain an area of debate and include limiting spinal range of motion, correcting posture and deformity, preventing gross trunk motion, increasing intraabdominal pressure, reducing force exerted by trunk muscles, providing softtissue massage and heat, and improving spinal proprioception..$^{5-7,19,20,24,33}$ Critics of lumbar supports have argued that bracing may provide workers with a false sense of support or allow muscles to atrophy, thereby increasing the potential for injury, particularly on discontinuation of use..$^{22,27}$ The clinical utility of lumbar bracing in the prevention and treatment of low-back pain remains controversial without conclusive evidence to support or refute the use of these devices. ${ }^{13,18}$

Braces have also been used in preoperative evaluation in an attempt to predict outcome following fusion surgery and used following lumbar surgery to promote a successful arthrodesis. ${ }^{8,14}$ Because lumbar orthoses do not eliminate motion in the lumbar spine, their utility has been questioned. ${ }^{2,3}$ The purpose of this review is to examine the medical evidence investigating the utility of brace therapy as strategy for prevention of low-back pain in the workplace, as a treatment for low-back pain, as a predictor of outcome following lumbar fusion surgery, and as an adjunct to lumbar fusion procedures.

\section{Search Criteria}

A computerized search of the National Library of Medicine database of the literature published from 2003 to 2011 was conducted using the following search terms: ("Lumbosacral Region [MeSH] OR "lumbar vertebrae [MeSH] or lumbar [title] or lumbosacral [title] AND ("low back pain [MeSH] OR "low back pain" [All Fields] OR "lower back pain" [All Fields] AND ("Orthotic Devices" [MeSH] OR "Braces" [MeSH] OR "brace" [title] OR "bracing" [title] OR "braces" [title]) AND ((“2003"[PDAT]: "3000" [PDAT]) AND "humans" [MeSH] AND English [lang]). After duplicates were discarded, 97 papers were identified, and their abstracts were reviewed. Eight relevant studies were identified and reviewed in detail, in addition to the 19 relevant studies from the previous guidelines. ${ }^{28}$ In our previous guidelines, regarding the use of bracing and external fixation for fusion, we identified 10 relevant studies using temporary external pedicle fixation (TEPF) to predict the response to fusion for low-back pain. Because of a significant complication rate (20\%-25\%) and the uncertainty of TEPF to predict outcome following lumbar fusion, TEPF was not recommended as a screening modality for patients suffering with low-back pain. It is not considered a routine modality, and further discussion was eliminated from this review. Several review papers, meta-analyses, biomechanical studies, technical notes, and small case series served to provide supporting data. The bibliography of each paper was reviewed and other relevant studies were identified. All clinical studies providing Level III medical evidence or better regarding the use of lumbar brace therapy for the prevention and treatment of low-back pain, for the prediction of outcome following lumbar fusion surgery, and as an adjunct to fusion surgery are summarized in Tables 1-4.

\section{Scientific Foundation}

\section{Bracing for Prevention of Low-Back Pain}

Lumbar braces have been used as a means of preventing either initial (primary prevention) or recurrent (secondary prevention) episodes of low-back pain in industrial workers. ${ }^{13,33}$ Van Poppel et al. randomized 282 individuals employed as baggage handlers into 4 groups: 1) education and lumbar brace, 2) education, 3) lumbar brace, and 4) no intervention. ${ }^{34}$ Employees in Groups 1 and 3 wore soft lumbar braces for a 6 -month period while working. For the entire cohort, there was no decrease in the incidence of reported back pain $(36 \%$ for braced individuals and $34 \%$ for nonbraced) or in the number of workdays lost when comparing braced with nonbraced workers. A subgroup analysis of workers with a history of back pain revealed that the use of a soft lumbar brace reduced the number of days lost due to back pain from 6.5 to 1.2 days per month $(\mathrm{p}=0.03)$. It should be noted that only $43 \%$ of the workers complied with the bracing protocol. Within the bracing cohort, there was no difference in the incidence of low-back pain or number of sick days among workers who complied and those who did not comply with the bracing protocol. The authors concluded that brace therapy does not diminish the incidence of lowback pain or time lost from work when used as a preventive strategy. The use of a lumbar support by workers with a previous history of low-back injury may reduce days lost due to low-back pain. Because of the high number of noncompliant workers, this study is considered to provide Level II medical evidence.

Reddell and colleagues randomized 642 individuals employed as baggage handlers into 4 groups: 1) education, 2) weightlifting belt-type brace, 3) education and brace, and 4) no intervention. ${ }^{27}$ During an 8-month period, the authors examined the total incidence of reported low-back injury, lost or restricted workdays due to lowback pain, and Workers' Compensation claims related to low-back pain. They found no differences among the 
Part 14: Brace therapy

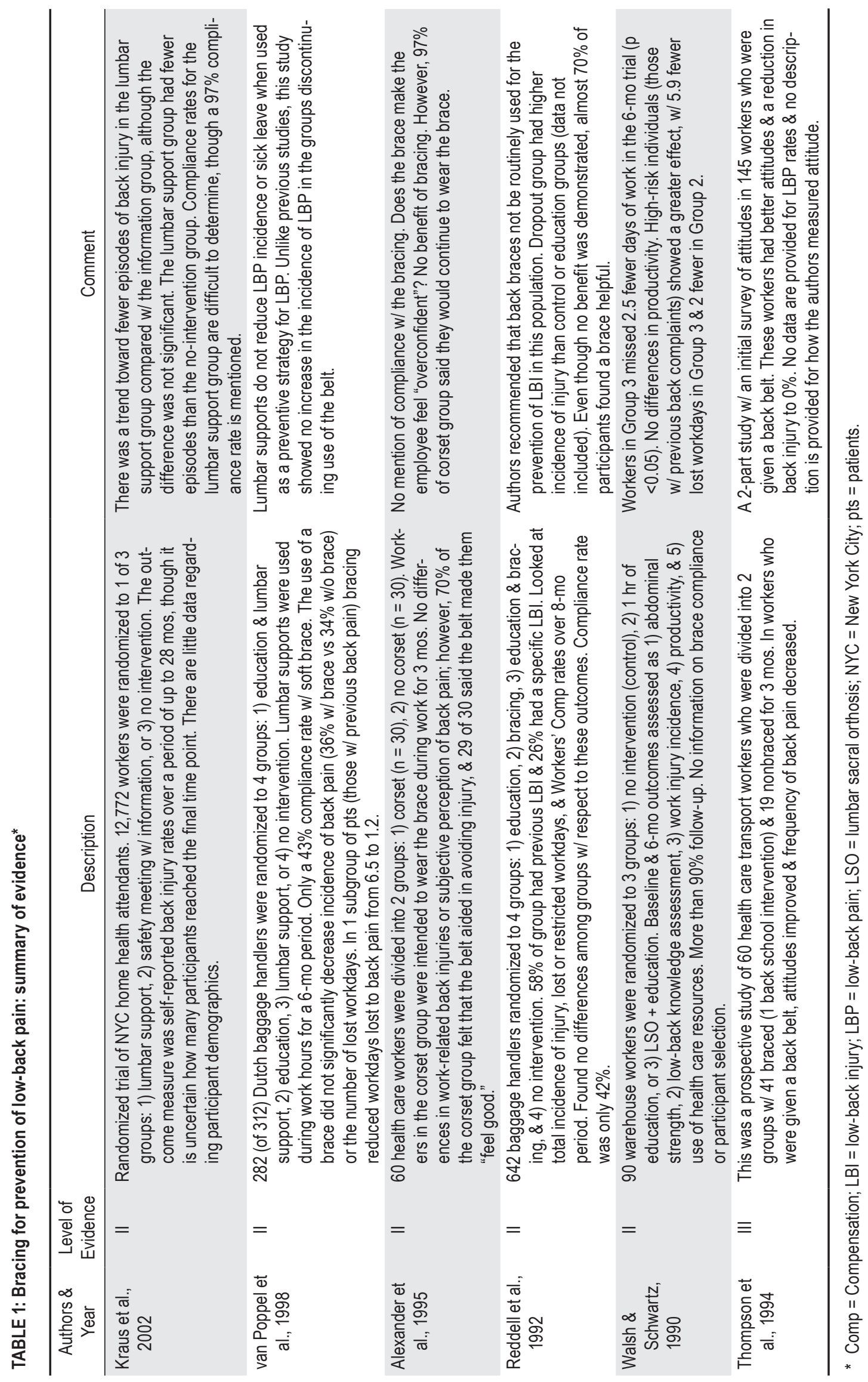


A. T. Dailey et al.

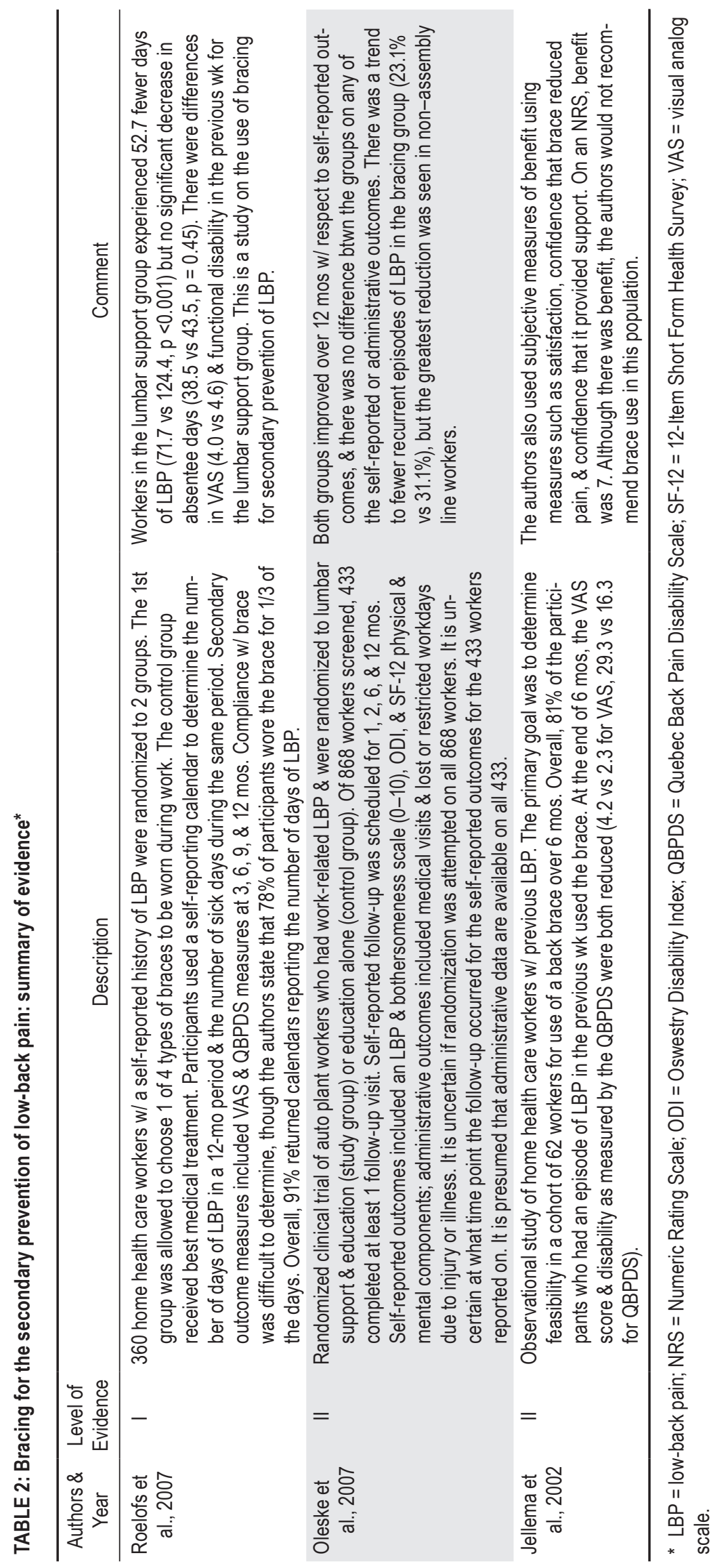


Part 14: Brace therapy

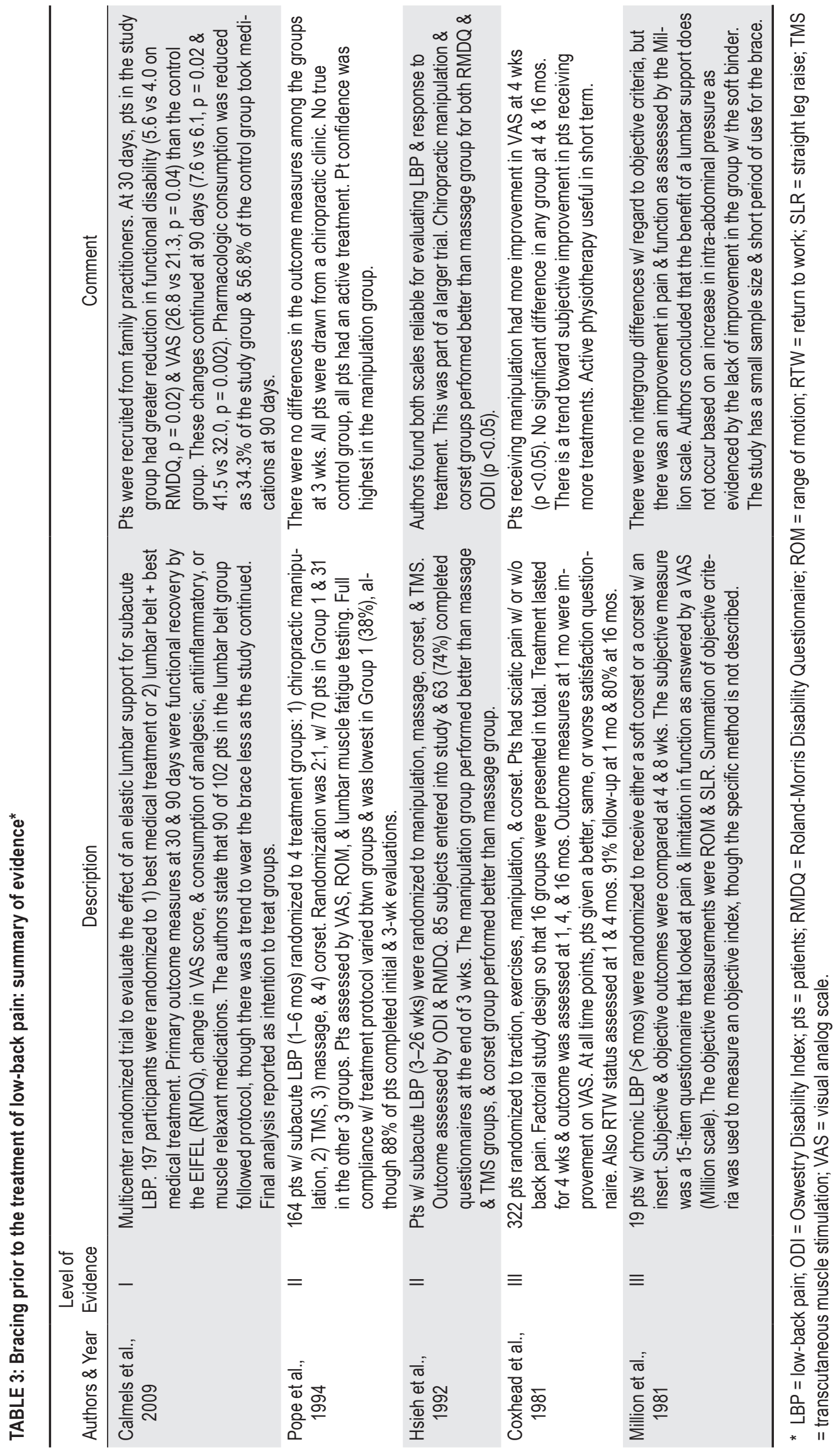


A. T. Dailey et al.

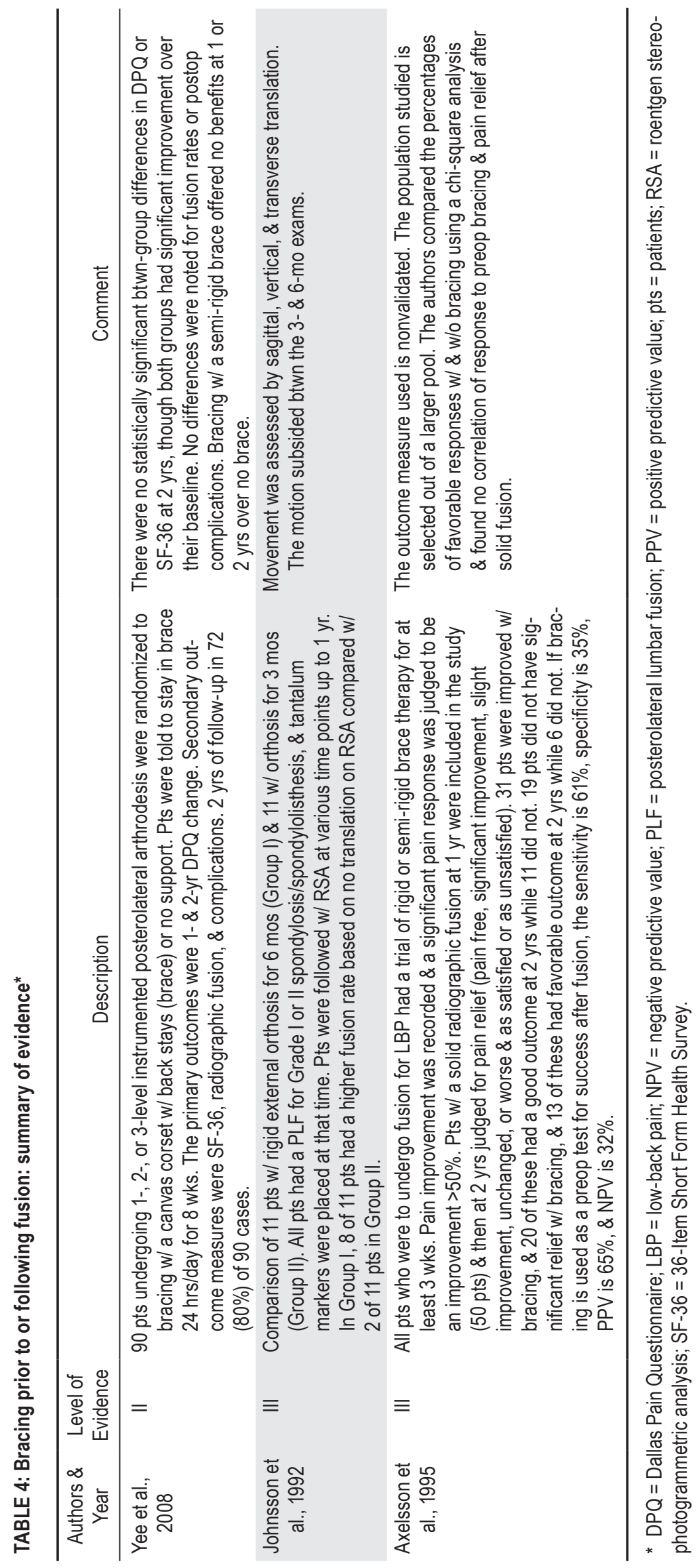


groups with respect to these outcome measures. Similar to the study by van Poppel and colleagues, only $42 \%$ of the individuals in the brace-treated groups were compliant with the use of the brace. The noncompliant group (158 individuals) was followed and found to have a higher incidence of lost workdays following discontinuation of the brace, but the difference between the compliant and noncompliant groups was not significant. This study also provides Level II medical evidence suggesting no benefit for the use of a lumbar orthosis to prevent back injury.

Kraus et al. randomized 12,772 New York City home health attendant workers to 3 groups: 1) lumbar bracing, 2) safety meeting with information, or 3) no intervention at all. ${ }^{17}$ The outcome measure was self-reported back injury rates over a period of up to 28 months. The bracing group had fewer episodes of low-back pain than the participants receiving no intervention (rate ratio $1.36,95 \%$ CI 1.02-1.82), and there was a trend toward fewer episodes in the lumbar support group than the information group, although the difference was not significant. Due to randomization techniques and lack of information on the demographic characteristics of the study participants, the follow-up time points reached, and compliance rates, this study offers Level II evidence on the use of bracing as a strategy for primary prevention of low-back pain in home health attendants. The authors also found that the strongest risk factor for low-back injury was a prior back injury, with a 3.1 risk ratio in this population, suggesting that lumbar braces may have an even greater role in secondary prevention of low-back pain. ${ }^{16,17}$

Alexander et al. reported the results of a small prospective randomized study of 60 health care workers divided into 2 groups. ${ }^{1}$ One group was assigned to wear a lumbar corset for a 3-month period. No differences in work-related back injuries or perception of back pain were noted. This study was downgraded to Level II evidence due to the use of a nonvalidated outcome measure but does suggest that a corset-type orthosis is not an effective measure to prevent low-back pain.

Walsh and Schwartz reported on a group of 90 warehouse workers who were randomly assigned to 3 groups: 1) no intervention; 2) 1-hour education; or 3) 6-month lumbosacral molded semi-rigid orthosis therapy and education. ${ }^{36}$ Outcomes were assessed using various measures, including work injury incidence, work productivity, and utilization of health care resources. Brace-treated workers missed 2.5 days less work $(p=0.03)$ than those not wearing braces (control and education-only groups), but there were no statistically significant differences between the groups with respect to productivity or utilization of health care resources. A subgroup analysis revealed that the benefit in terms of number of lost workdays was greatest in patients with a previous back injury. The authors concluded that the combination of brace therapy and education was effective in reducing lost workdays, especially among patients with a history of back injury. Limitations of this study include failure to incorporate validated outcome measures and failure to describe worker compliance with the bracing routine. Therefore, this study is considered to provide Level II evidence in support of brace therapy as an alternative for prevention of low-back pain.
Post hoc analysis from many of the initial studies on the efficacy of bracing for the prevention of low-back pain (primary prevention) revealed that the strongest benefit for lumbar bracing was derived from workers with a prior history of low-back pain.,16,17,36 Therefore, more recent studies have been designed to look specifically at the utility of lumbar bracing in workers with a prior history of low-back pain (secondary prevention of lowback pain). Roelofs et al. studied the use of bracing in 360 home health workers with a history of back pain, defined as current back pain or 2 or more episodes of low-back pain in the previous year. ${ }^{29}$ Workers were assigned to a short course on healthy working methods with or without use of a brace. Over 12 months, the group of workers who were assigned to use of a brace had 52.7 fewer self-reported days with low-back pain (95\% CI -59.6 to -45.1), but there was no statistically significant difference between the groups in days of sick leave (38.5 vs $43.5,95 \%$ CI -21.1 to 6.8$)$. Secondary outcome measures included VAS, Quebec Back Pain Disability Scale measures, and self-reported low-back pain-related sick days at 3, 6, 9, and 12 months. The bracing group had a lower mean VAS for low-back pain (4.0 vs 4.6, $\mathrm{p}=0.02)$, better mean disability rating (26.2 vs $30.3, p=0.017)$, and fewer days of low-back pain-related sick leave (3.2 vs 8.0, p = $0.003)$. The use of a back brace was at the discretion of the worker and only a rough estimate of use was given, suggesting the workers used the brace about one-third of the time, although the authors report an adherence rate of $78 \%$. The baseline characteristics of the 2 groups were very similar, and $91 \%$ of participants returned self-reported low-back pain calendars. Therefore, this study is considered to provide Level I evidence on the benefits of the prescription of bracing for limiting the number of days of low-back pain in home health workers with a prior history of low-back pain.

Oleske and colleagues performed a randomized clinical trial involving auto plant workers who had work-related low-back pain and were randomly assigned to lumbar support and education (study group) or education alone (control group). ${ }^{25}$ Of 868 workers screened, 433 workers completed at least 1 follow-up visit. Self-reported outcome follow-up was scheduled for 1, 2,6, and 12 months. Self-reported outcome measures included a low-back pain and bothersomeness scale (0-10), the Oswestry Disability Index (ODI), and the physical and mental components of the 12-Item Short Form Health Survey (SF-12); administrative outcomes included medical visits and lost or restricted workdays due to injury or illness. It is uncertain whether randomization was attempted for all 868 workers. With respect to the 433 participants on whom the authors reported, it is uncertain at what time point the follow-up occurred for the self-reported outcomes. It is presumed that administrative data are available for all 433 participants. Both groups reported significant declines in low-back pain (VAS), disability (ODI), and neurogenic symptoms and improvement in overall physical health (SF-12 scores) over 12 months. There was no significant difference in the number of lost or restricted workdays between the groups. There was a trend toward fewer episodes of low-back pain in the brace group $(23.1 \%$ 


\section{A. T. Dailey et al.}

vs $31.1 \%, p=0.059$ ). A subgroup analysis showed a significant decline in the number of recurrent episodes in the non-assembly line workers receiving a brace $(34.9 \%$ vs $63.1 \%, p=0.016)$. Because of the uncertainties in the randomization, the dropout rate of $50 \%$, and the lack of clarity regarding the number of workers who achieved 6 or 12 months of follow-up, this study is considered to provide Level II evidence that braces have no impact on lost work time, disability, or medical utilization in a general working population.

Jellema et al. performed an observational study on a cohort of home health care workers who had previous low-back pain. ${ }^{12}$ The primary goal was to determine feasibility in a cohort of 62 workers for use of a back brace over 6 months. Overall, $81 \%$ of the participants who had an episode of low-back pain in the previous week used the brace. At the end of 6 months, the authors observed a 44\% reduction in both the mean VAS pain score (4.2 vs 2.3 ) and the mean disability score as measured by the Quebec Back Pain Disability Scale (29.3 vs 16.3). Although there was a dropout rate of $20 \%$ due to a relatively small sample size, the study provides Level II evidence that bracing is a feasible option in home health care workers with prior low-back pain. The authors, however, recommended a prospective randomized trial to further determine the role of bracing in this population.

Several historical cohort studies have examined the incidence of back pain and days lost to work in groups of workers before and after they were issued a brace or lumbar support belt by their employer. Analysis of these studies revealed mixed results. One study identified no change in the incidence of back pain and sick days after braces were issued, and 2 studies reported a reduction in these parameters following the issue of a lumbar support to employees. ${ }^{16,23,30}$ Overall, the medical evidence supporting the use of braces for prevention of low-back pain is inconsistent. The authors of several systematic literature reviews have concluded that lumbar support devices are not useful for the prevention of low-back pain in the general working population. . $^{13,32,35}$ It does appear, however, that braces may be useful as a measure to decrease the number of sick days lost due to low-back pain in workers with a history of low-back injury (secondary prevention).

\section{Bracing for the Treatment of Low-Back Pain}

There have been several randomized control trials investigating the role of bracing as a treatment for low-back pain. A multicenter randomized trial by Calmels et al. evaluated the effect of an elastic lumbar support for subacute low-back pain. ${ }^{5}$ One hundred ninety-seven participants were randomized to best medical treatment or best medical treatment supplemented with the elastic lumbar support. Primary outcome measures at 30 and 90 days were functional recovery by the EIFEL (French version of the Roland-Morris Disability Questionnaire [RMDQ]), change in pain VAS score, and consumption of analgesic and anti-inflammatory medications or muscle relaxants. At 30 days, patients in the study group had greater reduction in functional disability (5.6 vs 4.0 on RMDQ, p $=0.02)$ and VAS (26.8 vs. $21.3, p=0.04)$ than the control group. These changes continued at 90 days (7.6 vs
$6.1, \mathrm{p}=0.02$, and 41.5 vs $32.0, \mathrm{p}=0.002)$. Consumption of pharmaceutical agents was reduced, as $34.3 \%$ of the study group and $56.8 \%$ of the control group took medication at 90 days. There were few limitations identified within the study design and execution, and therefore this study is considered to provide Level I medical evidence in support of bracing for the short-term management of subacute low-back pain.

Valle-Jones and colleagues randomized 216 patients with nonspecific low-back pain of varying duration to lumbar brace therapy or activity modification for 3 weeks. ${ }^{31}$ Outcome measures included a VAS score for pain and disability. Patients were also asked to record usage of pain medication. Brace-treated patients were found to have more improvement in pain at rest, pain with activity, and pain at night between Days 7 and 21. In addition, brace-treated patients took half the number of doses of paracetamol during the 21-day trial period compared with the control group. Return-to-work rates were higher in the brace-treated group $(85 \%)$ than in the control group $(67 \%, \mathrm{p}<0.02)$. The inclusion of diverse patient populations (acute and chronic low-back pain), the use of nonvalidated outcome measures (a 7-point VAS), and lack of data detract from the trial. This paper is considered to provide Level II medical evidence supporting the efficacy of braces for the short-term amelioration of low-back pain.

Pope et al. studied 164 patients with low-back pain drawn from a chiropractic clinic. Patients were randomized to 4 treatments: 1) chiropractic manipulation; 2) transcutaneous muscle stimulation (TMS); 3) massage; and 4) lumbar corset. ${ }^{26}$ Patients were assessed for pain using a VAS and were also assessed for range of motion after 3 weeks of treatment. There were no differences among the groups. Because of the relatively small treatment groups ( 30 patients in 3 of the 4 groups) and selected patient population (from a chiropractic practice), this paper is considered to provide Level II medical evidence suggesting that braces are no more effective than other modalities used for the treatment of acute low-back pain. Hsieh et al. studied 63 patients with low-back pain of less than 6 months' duration. ${ }^{11}$ Patients were randomized to manipulation, massage, lumbar corset, or TMS treatment for 3 weeks. Functional outcomes were assessed with the ODI and RMDQ. The primary purpose of the study was to validate the disability scales. Chiropractic manipulation and corset performed better than massage for both RMDQ and ODI $(p<0.05)$. The small number of patients in each cohort and the lack of a power analysis limit the authors' conclusions. This paper provides Level II evidence supporting the role of short-term lumbar brace therapy in patients with acute or subacute low-back pain as compared with massage or TMS. No inferences can be drawn regarding the effect of braces for patients with chronic low-back pain.

Two randomized controlled studies published in 1981 provide information on lumbar brace therapy for low-back pain. Coxhead and coworkers performed a randomized study of 322 sciatica patients with or without low-back pain randomized to different treatment modalities, including traction, exercises, manipulation, corset brace, and combinations of these treatments for a total 
of 16 treatment groups. ${ }^{9}$ Treatments lasted for 4 weeks, and outcome was assessed at 1, 4, and 16 months by VAS, return-to-work status, and patient satisfaction criteria. No benefit, short or long term, was detected for the use of lumbar corset braces. Because the population was composed of patients with sciatica, no direct conclusions can be drawn with regard to the treatment of low-back pain. In a smaller cohort study of 19 patients with chronic lowback pain, Million et al. randomized patients to either a soft or rigid lumbar brace group for 4 weeks. ${ }^{21}$ A 15 -item questionnaire about pain and functional limitation on a VAS (Million scale) demonstrated a significant improvement $(\mathrm{p}=0.01)$ for the cohort of patients wearing a rigid brace at 4 and 8 weeks. Rigid lumbar bracing may therefore have some short-term benefit compared with soft bracing for the short-term treatment of low-back pain. Because there was no control group in this study, the paper is considered to provide Level III medical evidence regarding the efficacy of brace therapy for low-back pain.

\section{Bracing Prior to Fusion}

There has only been one study published that has investigated the role of preoperative brace therapy as a predictor for outcome following lumbar fusion. ${ }^{4}$ Axelsson et al. placed all patients who were scheduled to undergo a lumbar fusion for low-back pain in either a rigid or a semi-rigid brace for at least 3 weeks. Pain improvement was recorded, and 31 patients had a significant response, judged as an improvement in pain of at least 50\%. Only 50 patients with a solid radiographic posterolateral fusion on anteroposterior and lateral plain radiographs at 1 year were included in the study. Two years following surgery, these same patients were subjectively examined for pain relief and satisfaction. Of the 31 patients who had experienced significant improvement of pain with the preoperative corset, 20 had a good outcome at 2 years (pain free or significant improvement), whereas 11 patients had poor outcomes despite a favorable response to preoperative lumbar bracing. Nineteen patients did not have significant relief from the corset, and 13 of these reported a favorable outcome at 2 years. If lumbar bracing is used as a preoperative "prognostic test" for success after solid fusion, the sensitivity is $61 \%$, the specificity is $35 \%$, the positive predictive value is $65 \%$, and the negative predictive value is $32 \%$. Therefore, due to the poor diagnostic parameters, the use of lumbar bracing as a prognostic indicator of fusion outcome is not recommended. Because of the reliance on patient satisfaction scores, the select population studied (only patients with solid radiographic fusion), and the lack of a standardized bracing protocol, the medical evidence derived from this study is considered Level III.

\section{Bracing Following Fusion}

Until recently, there were no published studies that compared outcomes following lumbar fusion with and without the supplemental use of a lumbar orthosis. Yee et al. randomized 90 patients undergoing 1-, 2-, or 3-level instrumented PLF to 8 weeks of postoperative bracing with a canvas corset with back stays (brace) or no orthosis. ${ }^{37}$ Data from 1- and 2-year follow-up examinations were available for $72(80 \%)$ of the 90 patients. There were no statistically significant between-group differences in Dallas Pain Questionnaire (DPQ) or SF-36 results at 1 or 2 years, although both groups showed significant improvement compared with baseline. No differences were noted for fusion rates or postoperative complications. Due to the good compliance and follow-up rates and an appropriate study size based on the power calculation, this study is considered to provide Level I evidence that postoperative semi-rigid bracing offers no functional or radiographic benefit at 1 or 2 years after surgery for patients undergoing instrumented PLF.

Several authors have advocated the use of brace therapy following lumbar fusion surgery. ${ }^{8,14}$ Johnsson et al. have suggested a minimum 5-month period of bracing following noninstrumented lumbar fusion. ${ }^{15}$ They noted that patients who used a brace for 6 months following surgery had a higher fusion rate (8 of 11 patients) at 1 year than those who used a brace for 3 months (2 of 11), when fusion was assessed as lack of motion with roentgen stereophotogrammetric analysis (RSA). The authors found that sagittal and vertical translation decreased significantly as measured by RSA between 3 and 6 months following surgery. They interpreted this result as evidence that healing of a noninstrumented lumbar fusion occurs over a 6-month period. They presented no evidence, however, regarding the effect of lumbar bracing on the rate of lumbar spinal fusion or functional outcome.

\section{Summary}

Although conflicting reports have been presented in the literature regarding the utility of lumbar bracing for the prevention of low-back pain, lower-level evidence suggests that the prophylactic use of braces does not reduce the incidence of low-back pain or decrease the amount of lost productivity in the general working population. In the select population of workers with a history of a back injury, bracing appears to decrease the number of workdays lost due to back pain.

Lumbar bracing appears to be an effective treatment for acute low-back pain in select populations. They do not appear to be an effective treatment strategy for chronic low-back pain. If a brace is used, rigid braces offer some benefit over soft braces. There are no data to suggest that relief of low-back pain with preoperative external bracing predicts a favorable outcome following lumbar spinal fusion. Bracing following instrumented lumbar fusion for degenerative disease does not appear to improve fusion rates or clinical outcomes.

\section{Key Issues for Future Investigation}

The most relevant questions for the spine surgeon may be related to the predictive value of a trial of brace therapy to predict functional outcomes following lumbar fusion surgery and the ability of postoperative bracing to improve functional and radiographic outcomes of fusion surgery. Formalizing and performing an appropriate prognostic study to investigate the predictive value of bracing may prove to be too difficult to perform. To determine 


\section{A. T. Dailey et al.}

the efficacy of postoperative bracing, an RCT comparing patients undergoing similar lumbar fusion procedures, randomized to brace therapy or no such therapy, could provide additional high-quality evidence to address the effect of postoperative bracing on functional and radiographic outcome, although the sample size would have to be large to demonstrate a small improvement in outcome.

\section{Acknowledgments}

We would like to acknowledge the AANS/CNS Joint Guidelines Committee (JGC) for their review, comments, and suggestions; Laura Mitchell, CNS Guidelines Project Manager, for her organizational assistance; and Linda O'Dwyer, medical librarian, for assistance with the literature searches. We would also like to acknowledge the following individual JGC members for their contributions throughout the review process: Timothy Ryken, M.D.; Kevin Cockroft, M.D.; Sepideh Amin-Hanjani, M.D.; Steven N. Kalkanis, M.D.; John O’Toole, M.D., M.S.; Steven Casha, M.D., Ph.D.; Aaron Filler, M.D., Ph.D., F.R.C.S.; Daniel Hoh, M.D.; Steven Hwang, M.D.; Todd McCall, M.D.; Jeffrey J. Olson, M.D.; Julie Pilitsis, M.D., Ph.D.; Joshua Rosenow, M.D.; and Christopher Winfree, M.D.

\section{Disclosure}

Administrative costs of this project were funded by the Congress of Neurological Surgeons and the Joint Section on Disorders of the Spine and Peripheral Nerves of the American Association of Neurological Surgeons and Congress of Neurological Surgeons. No author received payment or honorarium for time devoted to this project. Dr. Ghogawala receives grants from the Patient Centered Outcomes Research Institute (PCORI) and the National Institutes of Health (NIH). Dr. Groff is a consultant for DePuy Spine and EBI Spine. Dr. Mummaneni owns stock in Spinicity and receives honoraria from DePuy Spine and Globus and royalties from DePuy Spine, Quality Medical Publishers, and Thieme Publishing. Dr. Wang owns stock in Bone Biologics, AxioMed, Amedica, CoreSpine, Expanding Orthopedics, Pioneer, Syndicom, VG Innovations, PearlDiver, Flexuspine, Axis, FzioMed, Benvenue, Promethean, Nexgen, ElectroCore, and Surgitech and holds patents with and receives royalties from Biomet, Stryker, SeaSpine, Aesculap, Osprey, Amedica, Synthes, and Alphatec. The authors report no other potential conflicts of interest concerning the materials or methods used in this study or the findings specified in this paper.

Author contributions to the study and manuscript preparation include the following. Acquisition of data: all authors. Analysis and interpretation of data: all authors. Drafting the article: Dailey. Critically revising the article: all authors. Reviewed submitted version of manuscript: all authors. Approved the final version of the manuscript on behalf of all authors: Dailey. Study supervision: Kaiser.

\section{References}

1. Alexander A, Woolley SM, Bisesi M, Schaub E: The effectiveness of back belts on occupational back injuries and worker perception. Professional Safety 40:22-26, 1995

2. Axelsson P, Johnsson R, Strömqvist B: Effect of lumbar orthosis on intervertebral mobility. A roentgen stereophotogrammetric analysis. Spine (Phila Pa 1976) 17:678-681, 1992

3. Axelsson P, Johnsson R, Strömqvist B: Lumbar orthosis with unilateral hip immobilization. Effect on intervertebral mobility determined by roentgen stereophotogrammetric analysis. Spine (Phila Pa 1976) 18:876-879, 1993

4. Axelsson P, Johnsson R, Strömqvist B, Nilsson LT, Akesson M: Orthosis as prognostic instrument in lumbar fusion: no predictive value in 50 cases followed prospectively. J Spinal Disord 8:284-288, 1995
5. Calmels P, Queneau P, Hamonet C, Le Pen C, Maurel F, Lerouvreur $\mathrm{C}$, et al: Effectiveness of a lumbar belt in subacute low back pain: an open, multicentric, and randomized clinical study. Spine (Phila Pa 1976) 34:215-220, 2009

6. Cholewicki J: The effects of lumbosacral orthoses on spine stability: what changes in EMG can be expected? J Orthop Res 22:1150-1155, 2004

7. Cholewicki J, Shah KR, McGill KC: The effects of a 3-week use of lumbosacral orthoses on proprioception in the lumbar spine. J Orthop Sports Phys Ther 36:225-231, 2006

8. Connolly PJ, Grob D: Bracing of patients after fusion for degenerative problems of the lumbar spine-yes or no? Spine (Phila Pa 1976) 23:1426-1428, 1998

9. Coxhead CE, Inskip H, Meade TW, North WR, Troup JD: Multicentre trial of physiotherapy in the management of sciatic symptoms. Lancet 1:1065-1068, 1981

10. Dillingham TR: Lumbar supports for prevention of low back pain in the workplace. JAMA 279:1826-1828, 1998

11. Hsieh CY, Phillips RB, Adams AH, Pope MH: Functional outcomes of low back pain: comparison of four treatment groups in a randomized controlled trial. J Manipulative Physiol Ther 15:4-9, 1992

12. Jellema P, Bierma-Zeinstra SM, Van Poppel MN, Bernsen RM, Koes BW: Feasibility of lumbar supports for home care workers with low back pain. Occup Med (Lond) 52:317-323, 2002

13. Jellema P, van Tulder MW, van Poppel MN, Nachemson AL, Bouter LM: Lumbar supports for prevention and treatment of low back pain: a systematic review within the framework of the Cochrane Back Review Group. Spine (Phila Pa 1976) 26: 377-386, 2001

14. Johnsson R: The use of orthoses in lumbar spine fusion. Acta Orthop Scand Suppl 251:92-93, 1993

15. Johnsson R, Strömqvist B, Axelsson P, Selvik G: Influence of spinal immobilization on consolidation of posterolateral lumbosacral fusion. A roentgen stereophotogrammetric and radiographic analysis. Spine (Phila Pa 1976) 17:16-21, 1992

16. Kraus JF, Brown KA, McArthur DL, Peek-Asa C, Samaniego L, Kraus C: Reduction of acute low back injuries by use of back supports. Int J Occup Environ Health 2:264-273, 1996

17. Kraus JF, Schaffer KB, Rice T, Maroosis J, Harper J: A field trial of back belts to reduce the incidence of acute low back injuries in New York City home attendants. Int J Occup Environ Health 8:97-104, 2002

18. Lahad A, Malter AD, Berg AO, Deyo RA: The effectiveness of four interventions for the prevention of low back pain. JAMA 272:1286-1291, 1994

19. Lantz SA, Schultz AB: Lumbar spine orthosis wearing. I. Restriction of gross body motions. Spine (Phila Pa 1976) 11: 834-837, 1986

20. Lantz SA, Schultz AB: Lumbar spine orthosis wearing. II. Effect on trunk muscle myoelectric activity. Spine (Phila Pa 1976) 11:838-842, 1986

21. Million R, Nilsen KH, Jayson MI, Baker RD: Evaluation of low back pain and assessment of lumbar corsets with and without back supports. Ann Rheum Dis 40:449-454, 1981

22. Minor SD: Use of back belts in occupational settings. Phys Ther 76:403-408, 1996

23. Mitchell LV, Lawler FH, Bowen D, Mote W, Asundi P, Purswell J: Effectiveness and cost-effectiveness of employer-issued back belts in areas of high risk for back injury. J Occup Med 36:90-94, 1994

24. Nachemson AL: Orthotic treatment for injuries and diseases of the spinal column. Phys Med Rehabil 1:11-24, 1987

25. Oleske DM, Lavender SA, Andersson GB, Kwasny MM: Are back supports plus education more effective than education alone in promoting recovery from low back pain?: Results from a randomized clinical trial. Spine (Phila Pa 1976) 32:2050_ 2057,2007 


\section{Part 14: Brace therapy}

26. Pope MH, Phillips RB, Haugh LD, Hsieh CY, MacDonald L, Haldeman S: A prospective randomized three-week trial of spinal manipulation, transcutaneous muscle stimulation, massage and corset in the treatment of subacute low back pain. Spine (Phila Pa 1976) 19:2571-2577, 1994

27. Reddell CR, Congleton JJ, Huchingson RD, Montgomery JF: An evaluation of a weightlifting belt and back injury prevention training class for airline baggage handlers. Appl Ergon 23:319-329, 1992

28. Resnick DK, Choudhri TF, Dailey AT, Groff MW, Khoo L, Matz PG, et al: Guidelines for the performance of fusion procedures for degenerative disease of the lumbar spine. Part 14: brace therapy as an adjunct to or substitute for lumbar fusion. J Neurosurg Spine 2:716-724, 2005

29. Roelofs PD, Bierma-Zeinstra SM, van Poppel MN, Jellema P, Willemsen SP, van Tulder MW, et al: Lumbar supports to prevent recurrent low back pain among home care workers: a randomized trial. Ann Intern Med 147:685-692, 2007

30. Thompson L, Pati AB, Davidson H, Hirsh D: Attitudes and back belts in the workplace. Work 4:22-27, 1994

31. Valle-Jones JC, Walsh H, O'Hara J, O'Hara H, Davey NB, Hopkin-Richards H: Controlled trial of a back support ('Lumbotrain') in patients with non-specific low back pain. Curr Med Res Opin 12:604-613, 1992

32. van Duijvenbode IC, Jellema P, van Poppel MN, van Tulder MW: Lumbar supports for prevention and treatment of low back pain. Cochrane Database Syst Rev (2):CD001823, 2008
33. van Poppel MN, de Looze MP, Koes BW, Smid T, Bouter LM: Mechanisms of action of lumbar supports: a systematic review. Spine (Phila Pa 1976) 25:2103-2113, 2000

34. van Poppel MN, Koes BW, Devillé W, Smid T, Bouter LM: Risk factors for back pain incidence in industry: a prospective study. Pain 77:81-86, 1998

35. Van Tulder MW, Jellema P, van Poppel MN, Nachemson AL, Bouter LM: Lumbar supports for prevention and treatment of low back pain. Cochrane Database Syst Rev (3):CD001823, 2000

36. Walsh NE, Schwartz RK: The influence of prophylactic orthoses on abdominal strength and low back injury in the workplace. Am J Phys Med Rehabil 69:245-250, 1990

37. Yee AJ, Yoo JU, Marsolais EB, Carlson G, Poe-Kochert C, Bohlman HH, et al: Use of a postoperative lumbar corset after lumbar spinal arthrodesis for degenerative conditions of the spine. A prospective randomized trial. J Bone Joint Surg Am 90:2062-2068, 2008

Manuscript submitted March 17, 2014.

Accepted April 9, 2014.

Please include this information when citing this paper: DOI: 10.3171/2014.4.SPINE14282.

Address correspondence to: Michael G. Kaiser, M.D., Columbia University, Neurological Surgery, The Neurological Institute, 710 W. 168th St., New York, NY 10032. email: mgk7@columbia.edu. 